BMJ Open

Sport \&

Exercise

Medicine

\section{Preparing for snow-sport events at the Paralympic Games in Beijing in 2022: recommendations and remaining questions}

To cite: Fagher K, Baumgart JK, Solli GS, et al. Preparing for snow-sport events at the Paralympic Games in Beijing in 2022: recommendations and remaining questions. BMJ Open Sport \& Exercise Medicine 2022;8:e001294. doi:10.1136/ bmjsem-2021-001294

Accepted 4 February 2022

\section{Check for updates}

(C) Author(s) (or their employer(s)) 2022. Re-use permitted under CC BY-NC. No commercial re-use. See rights and permissions. Published by BMJ.

${ }^{1}$ Department of Health Sciences, Lund University, Lund, Sweden

${ }^{2}$ The Swedish Paralympic

Committee, Stockholm, Sweden ${ }^{3}$ Department of Neuromedicine and Movement Science,

Norwegian University of Science and Technology, Trondheim,

Norway

${ }^{4}$ Department of Sports Science and Physical Education, Nord University, Bodo, Norway ${ }^{5}$ Department of Health Sciences, Luleå University of Technology, Luleå, Sweden

${ }^{6}$ Department of Physiology and Pharmacology, Biomedicum C5, Karolinska Institutet, Stockholm, Sweden

${ }^{7}$ The Medical Committee, The International Paralympic Committee, Bonn, Germany

Correspondence to Dr K Fagher;

kristina.fagher@med.lu.se

\section{ABSTRACT}

During the 2022 Winter Paralympic Games in Beijing, the Para snow-sport events will be held at high altitudes and in possibly cold conditions while also requiring adjustment to several time zones. Furthermore, the ongoing COVID-19 pandemic may lead to suboptimal preparations. Another concern is the high rate of injuries that have been reported in the Para alpine and snowboard events. In addition to these challenges, Para athletes various impairments may affect both sports-specific demands and athlete health However, the group of Para snow-sport athletes is an understudied population. Accordingly, this perspective paper summarises current knowledge to consider when preparing for the Paralympic Games in Beijing and point out important unanswered questions. We here focus specifically on how sport-specific demands and impairment-related considerations are influenced by altitude acclimatisation, cold conditions, travel fatigue and jetlag, complications due to the COVID-19 pandemic, and injury prevention and sports safety considerations. As Para athletes with spinal cord injury, limb deficiency, cerebral palsy and visual impairment account for the majority of the Para snow-sport athletes, the focus is mainly on these impairment groups. In brief, we highlight the extra caution required to ensure athlete health, performance and sports safety among Para athletes participating in the snow-sport events in the 2022 Beijing Paralympic Games. Although there is an urgent need for more high-quality research focusing on Para winter athletes, we hope these non-consensus recommendations will help prepare for the 2022 Beijing Paralympic Winter Games.

\section{INTRODUCTION}

The 2022 Paralympic Winter Games in Beijing will be the first Games organised at high altitude $(\sim 1700 \mathrm{~m})$, with an expected number of around 750 athletes competing in two indoor (Para ice hockey, wheelchair curling) and four outdoor winter sports (Para snowboard, Para alpine skiing and Para Nordic skiing, which includesPara biathlon and Para crosscountry (XC) skiing). ${ }^{1}$ The combination of high altitude with cold and highly variable temperatures and dry air creates particularly

\section{Key messages}

What is already known

- The Para snow-sport event in the 2022 Winter Paralympic Games in Beijing will be held at high altitude, and in possibly cold conditions while also requiring adjustment to several time zones.

- In addition, Para athletes may face challenges related to the ongoing COVID-19 pandemic and the risk of other illnesses and injuries.

- Winter sports research is a growing field within the Olympic population, but there are few studies that have assessed performance and athlete health in winter Para sports.

\section{What are the new findings}

- Para athletes may experience impairment-related performance limitations and health issues related to the cardiorespiratory, metabolic and thermoregulatory systems.

- The Omicron VoC is considerably more contagious than the previous versions of the SARS-CoV-2 virus that was dominant during the Summer Paralympic Games, and the consequences of Omicron infection before and during the Paralympics are still disquieting.

- In the future, more sophisticated experiments and observational studies focusing specifically on Para winter sports are warranted.

challenging conditions for athletes competing in outdoor snow sports, which together account for $93 \%$ of the medals awarded during the Beijing Paralympic Winter Games. In addition, para athletes are more susceptible to injuries than Olympic athletes both during training and during competitions directly at Paralympic Games, with the highest injury rates in Para alpine and snowboard events during the previous Paralympic Winter Games. $^{2-4}$ Moreover, Para athletes from Europe and North and South America have to adjust to the new time zone after travelling long distances. Lastly, the ongoing COVID-19 pandemic requires modification of training 
programmes travelling itinerates and may reduce the size of the athletes' support team. Sudden changes in the competition programme may also occur right before or even during the Paralympic Winter Games themselves. Compared with Olympic winter sports athletes, the challenges related to high altitude, cold weather, risk of injury, travelling across time zones and the COVID-19 pandemic may be exacerbated in Para athletes due to impairmentrelated factors.

As researchers within the Paralympic field, this motivated us to present recommendations when preparing for the Paralympic Games in Beijing, focusing on outdoor snow sports and posing questions that future research should answer. We here put special emphasis on Para athletes with spinal cord injury (SCI), limb deficiency (ie, amputation and dysmelia), cerebral palsy (CP) and visual impairment (VI), who together account for the majority of the Paralympic winter sports athletes.

\section{SPORT-SPECIFIC DEMANDS}

Para XC skiing and biathlon are endurance sports, in which athletes compete in race courses consisting of undulating terrain with uphill, flat and downhill segments. In Para XC skiers, it has been shown that the varying terrain leads to substantial variation in speed, which is regulated by the selection of pacing strategies, subtechniques, and related kinematic patterns. ${ }^{56}$ While this has not yet been investigated for Para XC skiers and biathletes, the aerobic energy contribution during races is expected to be similar as in their able-bodied counterparts, and in the range of $80 \%-95 \% .^{7-10}$ Therefore, performance is mainly determined by a high peak oxygen uptake $\left(\dot{\mathrm{V}} \mathrm{O}_{2 \text { peak }}\right)$, the performance maximum rate of oxygen $\left(\dot{\mathrm{VO}}_{2 \max }\right.$ and exercise efficiency. ${ }^{911}$ In addition, Para biathletes need to pace their speed to optimise shooting performance while at the same time balancing this with high endurance performance demands.

Para alpine skiing and snowboard are technical sports, which place high demands on the athlete's technical skill, balance and motor control. ${ }^{12}{ }^{13}$ In addition, these sports challenge the athlete's strength, power, aerobic and anaerobic capacity. ${ }^{12} 13$ The demands of Para snowboarding athletes and Para alpine skiers that compete in the categories for standing or visually impaired athletes are similar to their able-bodied counterparts. ${ }^{14}$ For Para alpine skiers that compete in the sitting classes, it appears that the endurance and strength demands are lower, and the athlete-equipment interaction, as well as the interaction of the equipment with the external forces and the snow surface, might be even more crucial. ${ }^{14}$

\section{CLASSIFICATION}

Para athletes in the snow-sports events compete in different categories and classes to ensure fair competitions, depending on the functional limitations caused by their specific impairment (figure 1). The classification systems in Para XC skiing, Para biathlon and Para alpine skiing are similar, and athletes compete in three different categories: (1) physically impaired sitting skiers, (2) physically impaired standing skiers and (3) visually impaired standing skiers. Within each of these categories, athletes are further divided into several classes. Due to low numbers of athletes within classes, all classes in one category compete against each other, and a classspecific time factor is used to adjust the race time. In Para snowboard, there are two classes for athletes with lowerlimb impairments and one for athletes with upper-limb impairments. $^{15}$

\section{IMPAIRMENT-RELATED CONSIDERATIONS}

While athletes with different impairments but similar magnitude of functional limitations may compete in the same class, there are limitations in the above-described sport-specific demands, which are impairment-specific. These are summarised below for the most common impairment types; SCI, CP, limb deficiency and VI. While some athletes have unaffected cardiorespiratory, metabolic and thermoregulatory responses (eg, athletes with VIs), others exhibit markedly reduced responses (eg, athletes with thoracic and cervical SCI). In this context, it should be noted that the level of impairment of most of the Para winter sports athletes within each of these impairment types is rather mild.

\section{Spinal cord injury}

In endurance athletes with an SCI $\dot{\mathrm{VO}}_{2 \text { peak }}$ is 15\%-60\% lower than their able-bodied counterparts due to lower active muscle mass when exercising with the upper body only and due to cardiorespiratory limitations. ${ }^{16}$ Active muscle mass and cardiorespiratory function are increasingly affected by higher levels of the SCI. More specifically, athletes with a motor and sensory complete SCI at the Th6 level or above lack sympathetic innervation of the lower extremities and organs. ${ }^{17}$ This leads to a lack of vasoconstriction, which reduces blood redistribution to the active musculature. Furthermore, in athletes with tetraplegia, sympathetic innervation of the heart is affected, which may cause lower blood pressure and a lack of increase in heart rate during training and competitions. ${ }^{18}$ In line with the lower $\dot{\mathrm{VO}}_{2 \text { peak }}$, the $\dot{\mathrm{V}} \mathrm{O}_{2}$ at the anaerobic threshold is also lower in athletes with SCI due to exercising with a lower active muscle mass of the upper body. Accordingly, exercise efficiency was lower during upper- compared with lower-body exercise. ${ }^{19} 20$ However, exercise efficiency during upper-body exercise was not different in athletes with SCI compared with their able-bodied counterparts, that is, athletes with an SCI produced lower power output but also used proportionally less $\mathrm{VO}_{2}{ }^{21}$ While higher blood lactate concentration (BLa) values were found at a given speed or perceived exertion during upper- compared with lower-body exercise ${ }^{22}$ BLa clearance after exercise during upperbody exercise was similar for athletes with and without an SCI. ${ }^{23}$ Sport-specific demands in athletes with SCI may also be negatively affected by overuse injuries to the shoulder, osteoporosis, pressure ulcers, impaired 


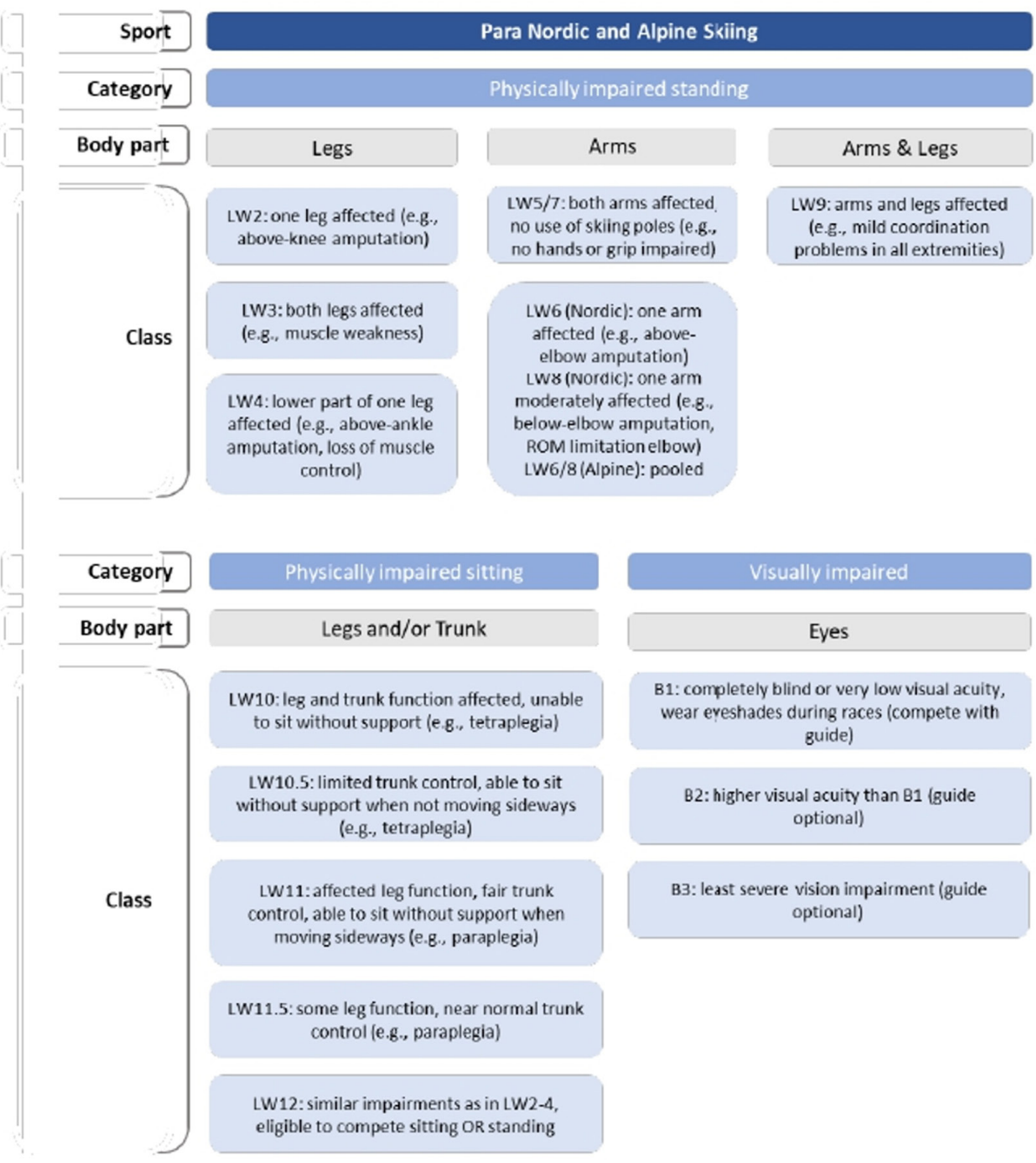

Figure 1 Categories and classes in Para Nordic Skiing (ie, cross-country skiing and biathlon), Para Alpine Skiing and Para Snowboard.

thermoregulation and neuropathic pain, factors that are presented more specifically in table 1.

\section{Limb deficiency}

Little research is available on individuals and athletes with upper-limb amputations, and this section, therefore, focuses on what is known for those with lower-limb amputations, which by extension should apply to those with dysmelia of the lower limb. Untrained individuals with a below-the-knee amputation were found to have similar $\dot{\mathrm{VO}}_{\text {2peak }}$ as compared with non-disabled individuals. ${ }^{24} \mathrm{At}$ the same time, $\dot{\mathrm{VO}}{ }_{2 \text { peak }}$ was $35 \%-40 \%$ lower in individuals with an above-the-knee amputation due to lower active muscle mass and limitations in attaining high walking/ running speed. ${ }^{25} 26$ While this has not yet been investigated, we expect reduced differences in $\dot{\mathrm{VO}}_{2 \text { peak }}$ between Para athletes with an above-the-knee amputation and non-disabled athletes. Furthermore, energy consumption at a given walking/running speed was reported to be higher in untrained individuals with below-the-knee and above-the-knee amputations compared with non-disabled individuals due to compensatory muscle activity. ${ }^{27}$
However, similar exercise efficiency was found in athletes with unilateral and bilateral amputations, ${ }^{28}$ indicating that high-level training can compensate for initial reductions in this parameter. Sport-specific demands in athletes with limb deficiency may also be negatively affected by stump-related issues and overuse injuries (table 1).

\section{Cerebral palsy}

Compared with able-bodied controls, endurance-trained adults with CP had $0.3 \%-21 \%$ lower peak oxygen uptake $\left.\left(\dot{\mathrm{VO}}_{\text {2peak }}\right)\right)^{29}$ This difference is considerably lower than other studies found when comparing untrained agematched controls with and without CP and highlights the positive effects of exercise. ${ }^{30}$ In addition, exercise efficiency is reduced in athletes with CP arguably due to muscle spasticity, decreased range of motion and pain. ${ }^{31} 32$ Anecdotally, higher BLa values at a given speed/power output have been reported in athletes with CP compared with able-bodied counterparts, which is likely related to the muscle spasticity negatively influencing the diffusion of blood from active muscle mass to venous blood. Furthermore, strength is reduced in athletes with CP 


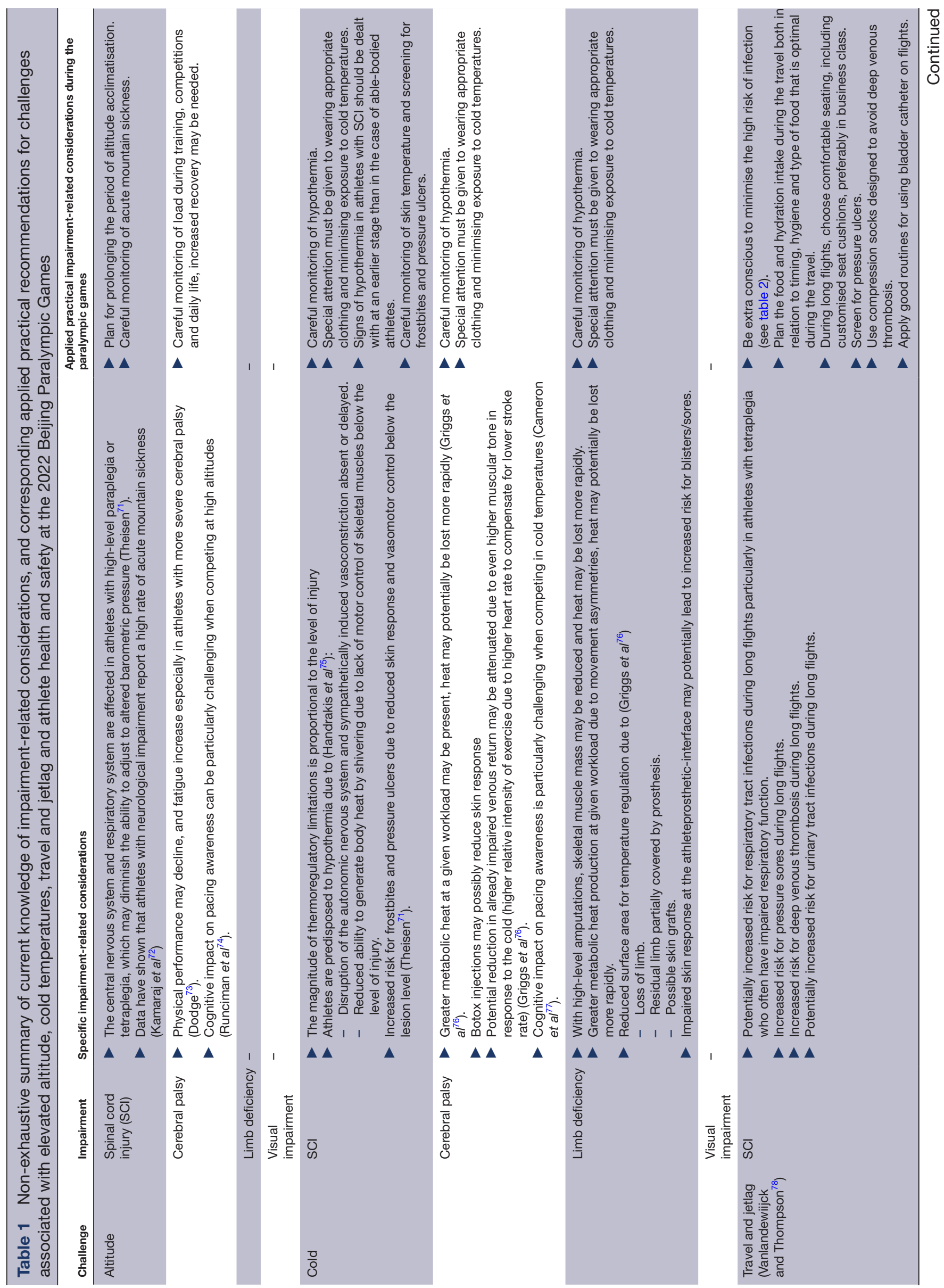




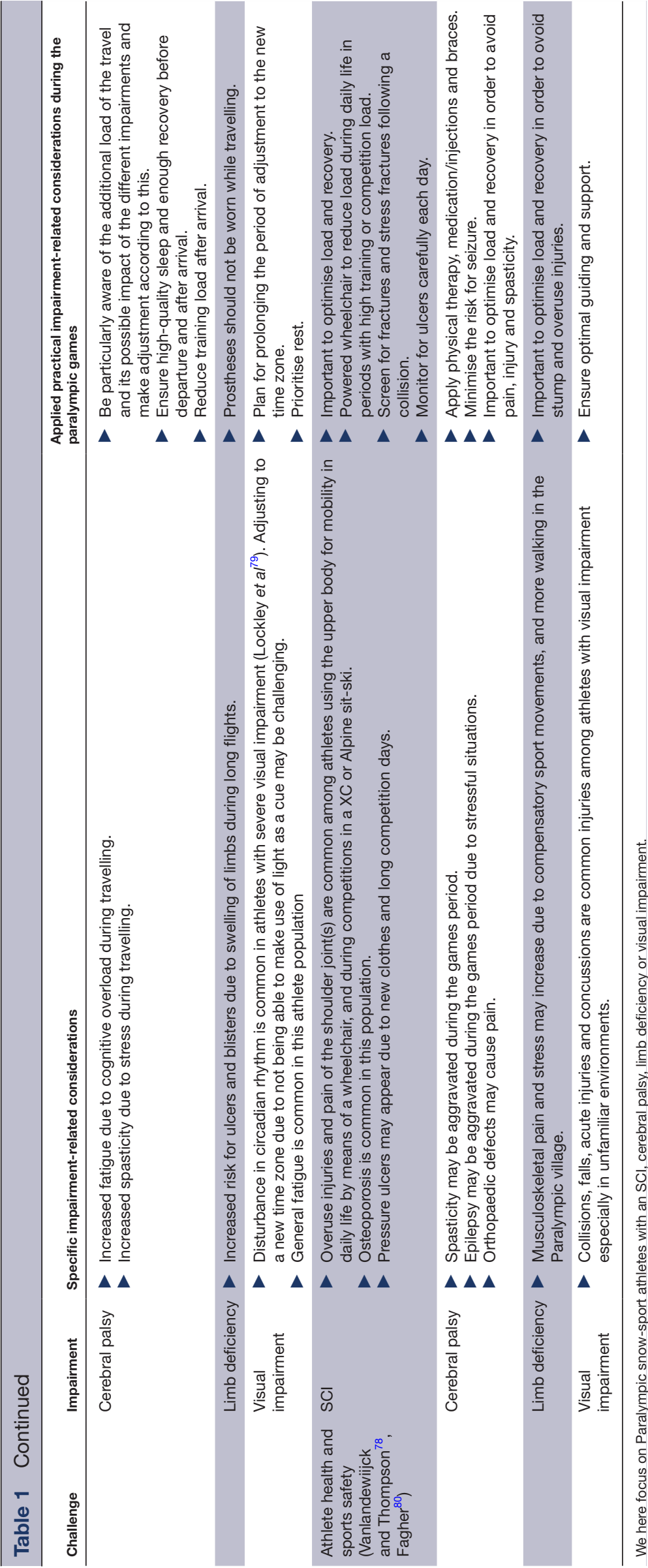


due to decreased central input caused by brain damage, coactivation of antagonists muscles, increased type 1 muscle fibres, increased intramuscular fat and muscle atrophy. ${ }^{33} 34$

\section{Visual impairment}

Compared with highly trained non-disabled individuals, partially or completely blind athletes showed around $15 \%$ lower $\dot{\mathrm{V}} \mathrm{O}_{2 \text { peak }},{ }^{35}{ }^{36}$ and lower exercise efficiency. ${ }^{36}$ This is most likely entirely related to lower locomotor efficiency and dynamic balance, ${ }^{37} 38$ since most VI athletes do not have cardiorespiratory limitations. For partially sighted athletes, the differences in $\dot{\mathrm{V}}_{\text {2peak }}$ and exercise efficiency compared with their able-bodied counterparts are expected to be lower than in fully blind athletes. Furthermore, athletes with VI may be negatively affected by fatigue, circadian rhythm disturbances and acute sports injuries (table 1).

\section{ALTITUDE ACCLIMATISATION}

\section{Effect of altitude on endurance performance}

At approximately $1700 \mathrm{~m}$, the partial pressures of nitrogen and oxygen are reduced, and only $79 \%$ and $21 \%$, respectively, of the amount at sea level, are available at this altitude. ${ }^{39}$ Bad weather conditions might further reduce these partial pressures. The effects of altitude can be divided into (1) those affecting the interaction of the athletes and their equipment with the environment (ie, slightly less gravity and air drag) and (2) those affecting the human physiology due to less availability of oxygen. While the former effects are likely largest yet small in Para alpine skiing and Para snowboard, the effect of altitude on aerobic endurance is more pronounced and performance is particularly impacted in the endurance events. In the following, we will focus mainly on the effect of altitude on sport-specific demands of the (Para) endurance snow-sports.

In non-disabled endurance athletes, the saturation of blood with oxygen during maximal exercise declines by $5.5 \%$, and $\dot{\mathrm{V}} \mathrm{O}_{2 \max }$ by $6.3 \%(4.5 \%-7.5 \%)$ per $1000 \mathrm{~m}$ elevation in altitude. ${ }^{40}$ These decrements in maximal endurance capacity are highly individual, perhaps due to individual differences in hypoxic ventilatory responses or kinetics of oxygen delivery. ${ }^{41}$ While this has not yet been investigated in Para athletes, we expect similar or larger performance decrements depending on the type and level of impairment, speculatively with even larger interindividual variations due to the large impairment-related heterogeneity of Para athletes. Furthermore, increased ventilation and heart rate were found in non-disabled athletes when training and competing at elevated altitude, with similar or larger increases expected in Para athletes depending on the type and level of impairment. Accordingly, altitude-related increase in ventilation and heart rate may be particularly challenging for Para biathletes in connecting to shooting performance. ${ }^{11}$

Non-disabled and Para athletes alike often also experience that the duration and quality of their sleep are compromised at higher altitudes ${ }^{42}$ possibly due to respiratory events such as periodic breathing. ${ }^{43}$ The latter may be particularly concerning for Para athletes as it has been shown that this population already is predisposed to a greater risk of poor sleep due to impairment-related comorbidities. ${ }^{44}$

\section{Acclimatisation to altitude}

The long-term physiological adaptations to altitude include a rise in the level of erythropoietin and subsequent increases in the production of red blood cells (erythrocytes) and total mass of haemoglobin. ${ }^{3941}$ These changes were found to normally require at least $2-3$ weeks of altitude exposure in non-disabled athletes. ${ }^{45}{ }^{46}$ However, we will focus here solely on the influence of acclimatisation low-to-moderately elevated altitudes (eg, 1200-1800 m) on performance. Such 'short-term' performance improvements due to 10-14 days of acclimatisation may be achieved by more rapid and deeper breathing (referred to as hypoxic ventilatory response), both when resting and exercising. ${ }^{39}$ The accompanying increase in blood $\mathrm{pH}$ (respiratory alkalosis) limits this response but can be eliminated within 4-7 days through renal bicarbonate secretion, allowing subsequent chemoreceptor-mediated respiratory enhancement. ${ }^{39}$ However, the mechanisms related to possible performance improvements from acclimatisation are relatively unexplored.

In this context, when preparing for the Beijing Paralympic Games, various 'live low-train high' strategies ${ }^{47}$ rather than living and training at elevated altitude might be considered, ${ }^{39}$ especially with the travel restrictions designed to prevent the spread of COVID-19. This might involve intermittent or chronic hypoxia with or without accompanying exercise (eg, treadmill rollerskiing). Although no controlled comparisons have been made even in non-disabled athletes, there are some indications that living and training where the competitions will be held promotes more optimal acclimatisation, ${ }^{48}$ which is likely also the case for Para athletes.

In addition to altitude acclimatisation, athletes who have trained and competed at relevant altitudes before the Beijing Paralympics are likely to optimise warm-up procedures, pacing strategies, techniques and tactics much more effectively. For example, less oxygen availability enhances the risk for greater oxygen debt early in the competition, so pacing becomes more important. In this context, technological developments such as highly accurate global navigation satellite systems allow detailed analyses of training and competition that should help establish the relationship between the perceived and actual intensity of exercise. ${ }^{6}$

While table 2 summarises recommendations for optimal altitude acclimatisation in preparation for both the Beijing Olympic and Paralympic Games ${ }^{49}$ table 1 includes impairment-specific considerations and applied practical recommendations to be aware when Para athletes with SCI, CP, limb deficiency and VI acclimatise in advance to competitions at low-to-moderate altitudes. 
Table 2 Recommendations for optimising preparations of Olympic and Paralympic athletes in snow-sport events to challenges associated with elevated altitude, cold temperatures, travel and jetlag at the 2022 Beijing Olympic and Paralympic Games based on Sandbakk et al ${ }^{49}$ with minor modifications

\begin{tabular}{|c|c|c|}
\hline Challenge & General applied practical recommendations-long term & General applied practical recommendations-short term \\
\hline Altitude & $\begin{array}{l}\text { In advance, train for at least } 60 \text { days and participate in several } \\
\text { competitions at this elevation or higher. } \\
\text { Individualise training, recovery, pacing, technique and nutrition } \\
\text { appropriately. }\end{array}$ & $\begin{array}{l}\text { As close in time prior to the Games as possible, train for } 0-14 \text { days at the } \\
\text { altitude of competition, either at the actual venue for the Games or in Europe } \\
\text { or Asia (which will require later adjustment of the circadian rhythm). } \\
\text { Alternatively, live and train for } 14-21 \text { days above } 2000 \mathrm{~m} \text {, followed by } 7-10 \\
\text { days at } \sim 1700 \mathrm{~m} \text {. For maximal erythropoiesis, blood levels of ferritin should } \\
\text { be }>30 \mathrm{ng} / \mathrm{mL} \text { prior to exposure to altitude and oral supplementation with iron } \\
(\sim 100-200 \mathrm{mg} \text { daily) individualised during this exposure. } \\
\text { Acclimatisation and performance at elevated altitudes with maintenance of } \\
\text { good health is dependent on appropriate nutrition and hydration, and good } \\
\text { sleep hygiene and routines }\end{array}$ \\
\hline Cold & $\begin{array}{l}\text { Adapt individualised warm-up procedures, pacing strategies } \\
\text { and clothing to different temperatures and potentially changing } \\
\text { environmental conditions in an appropriate manner. }\end{array}$ & $\begin{array}{l}\text { Wear clothing that ensures maintenance of core body temperature. } \\
\text { Develop a strategy for maintaining body temperature effectively during the } \\
\text { interval between warm-up and competition. } \\
\text { Adapt individualised warm-up and pacing to prevailing environmental } \\
\text { conditions, especially at the beginning of a race. } \\
\text { Preparation must be made for treatment of asthmatic symptoms when } \\
\text { respiration is rapid at cold temperatures. }\end{array}$ \\
\hline
\end{tabular}

\begin{tabular}{|c|c|c|}
\hline $\begin{array}{l}\text { Travel and } \\
\text { jetlag }\end{array}$ & $\begin{array}{l}\text { Exposure yourself to (day)light in a manner that optimises } \\
\text { adjusting your circadian rhythm and consider dietary } \\
\text { supplementation with } 2-5 \mathrm{mg} \text { melatonin, if needed. } \\
\text { Schedule meals and social activities on the basis of the local } \\
\text { time. } \\
\text { Short ( } 20-30 \mathrm{~min} \text { ) naps can promote recovery and alertness. } \\
\text { During the initial few days, total training load should be } \\
\text { reduced and intensive high-intensity training avoided. }\end{array}$ & $\begin{array}{l}\text { Arrive at least } 1 \text { day earlier for each hour by which your time zone differs from } \\
\text { that in Beijing. } \\
\text { Before departure, shift your sleep and eating schedule by } 0.5-1 \text { hour daily for } \\
\text { three or } 4 \text { days towards the anticipated schedule in Beijing. } \\
\text { Travelling east during the afternoon and night increases the chances of } \\
\text { sleeping well during the flight. } \\
\text { Avoid dehydration by drinking appropriate volumes of fluids free from alcohol } \\
\text { or caffeine. } \\
\text { To minimise the high risk of infection associated with air travel, try to avoid } \\
\text { crowds and use a face mask when it is difficult to keep distance, wash your } \\
\text { hands frequently. }\end{array}$ \\
\hline $\begin{array}{l}\text { Athlete } \\
\text { health and } \\
\text { sport safety }\end{array}$ & $\begin{array}{l}\text { Monitor injuries and illnesses in detail, both during training } \\
\text { and the Olympic/Paralympic Games themselves to identify the } \\
\text { extent of the problem. } \\
\text { Work proactively with injury and disease prevention, athlete } \\
\text { health, and education within the Olympic/Paralympic } \\
\text { movement and the National Olympic/Paralympic Committees. }\end{array}$ & $\begin{array}{l}\text { Allow athletes to train on and test the actual competition courses in advance. } \\
\text { Do not hesitate to cancel or postpone competitions if the weather is too bad } \\
\text { or other conditions poor. } \\
\text { Adhere to the COVID-19 regulations put in place specifically for the } \\
\text { Paralympic Games. }\end{array}$ \\
\hline
\end{tabular}

In addition, we here provide general recommendations for athlete health and sport safety at the 2022 Beijing Olympic and Paralympic Games.

\section{PERFORMING IN THE COLD}

The ambient temperatures during the Beijing Paralympics may vary from $-15^{\circ}$ to plus degrees, with rapid changes from 1 day to another. Depending on the type and level of impairment, thermoregulation may be more challenging in Para athletes when adapting to cold temperatures of $-5^{\circ} \mathrm{C}$ to $-15^{\circ} \mathrm{C}$ or lower. In cold temperatures, especially in the presence of wind, the core body temperature rises, while skin temperature falls due to cooling the superficial musculature. ${ }^{50}$ Such cooling causes muscles to produce less aerobic energy and fatigue more rapidly and attenuate nerve and muscle excitability and nerve conduction, ${ }^{51}$ all of which may lower overall power production and may especially affect Para athletes due to the nature of various impairments (table 1).

Although endurance performance diminishes as the temperature falls, some studies on non-disabled athletes have reported no effects of ambient temperature on $\dot{\mathrm{V}} \mathrm{O}_{2 \max }{ }^{52} 53$ In contrast, other studies have observed reductions in $\dot{\mathrm{V}} \mathrm{O}_{2 \max }$ in cold temperatures. ${ }^{53-56}$ While relatively little is known concerning the effects of cold on endurance performance and related physiological mechanisms in Para snow-sport athletes, the negative effects of the cold on endurance performance are likely similar or enhanced depending on the type and level of the impairment. We describe impairment-specific considerations based on deductions from how the different impairments theoretically should be impacted by cold temperatures, in addition to applied recommendations that are experience-based on practices of many of the Para snow-sport teams (tables 1 and 2). Moreover, at altitudes of $\sim 1700 \mathrm{~m}$ or higher, the low humidity combined with cold air, as is often the case at the competition arenas used during the Beijing Olympic and Paralympic Games, challenges respiration. This is especially the case for Olympic and Paralympic athletes with asthma, which will require appropriate medication to at least in part compensate for asthma-related respiratory limitations.

\section{TRAVEL FATIGUE AND JET LAG}

Para athletes from Europe and North and South America will have to fly for $10-15$ hours across $\sim 8$ time zones to reach Beijing, experiencing travel fatigue and jet lag. Individuals react differently to the desynchronisation 
of established biological rhythms from the local time. The most common symptoms in non-disabled athletes are poor night-time sleep, tiredness during the day, loss of appetite, gastrointestinal disturbances and impaired mental/or physical performance. ${ }^{57-60}$ Several studies have also reported reduced performance in relation to travel fatigue and jet lag in able-bodied athletes. ${ }^{57} 58$ Furthermore, in able-bodied, it is well documented that international air travel is the single most important risk factor for upper respiratory tract and gastrointestinal infections. ${ }^{61}{ }^{62}$ Other travel risk factors include inadequate intake of nutrients and dehydration. ${ }^{61}$ While there is a lack of studies investigating these factors in Para athletes, they are likely exacerbated for many Para athletes due to the nature of their impairment, and accordingly, impairment-specific travel strategies and optimal recovery after travelling become even more crucial.

In non-disabled athletes, it is well documented that sleep deprivation leads to more errors, impaired decisionmaking, slower attainment of maximal power, greater fatigue and less ability to exercise maximally, while also increasing the risk of illness. ${ }^{63-65}$ Since sleep deprivation appears to be common among Para athletes, ${ }^{44}$ it may be of particular importance to ensure high sleep quantity and quality for several weeks or months before travelling to Beijing.

To reduce the impact of travel fatigue and jet lag on performance, we recommend that Para athletes, coaches and support staff consider actions before, under and after travel. Actions recommended for non-disabled athletes are discussed in more detail in a previously published study, ${ }^{49}$ and a summary is provided in table 2 . Furthermore, we here provide impairment-specific considerations and corresponding applied practical recommendations in table 1 .

\section{COMPLICATIONS DUE TO THE COVID-19 PANDEMIC}

The innumerable changes due to the global COVID-19 pandemic include limitations on athletic training and competition, and anecdotal evidence suggests that Para athletes have been even more affected than their ablebodied counterparts. While many Para athletes are at risk of suffering more severe consequences if they contract the coronavirus, infections rates during the Olympic and Paralympic Summer Games 2021 were very low $(0.003 \%)$ and symptoms were not significantly increased for Para athletes. ${ }^{66}$ A concern is, however, that the Omicron VoC is considerably more contagious than the previous versions of the SARS-CoV-2 virus. The global distribution of vaccines and growing natural immunity in populations reduce concerns about serious outcomes of infections. Nonetheless, the consequences of Omicron infection before the Paralympics are still disquieting. It is, therefore, important to have clear plans on how to manage symptomatic and asymptomatic athletes with positive COVID-19 test results at different points in time before and during the Paralympic Games. Moreover, it is crucial to establish psychological preparation of athletes that are not allowed to participate in the competitions due to a positive COVID-19 test even though they are asymptomatic. The strict isolation protocol for positive participants during the Paralympic Games can also expose some individuals to mental health issues, and it is important that each team has an established crisis plan that can support athletes and team officials that might be in quarantine in China for a longer period of time. Another important aspect is that it could be challenging for athletes with a visual or physical impairment to be isolated without their guide. At present, it is clear that this pandemic will affect the 2022 Beijing Paralympic Games, and in the meantime, athletes and coaches must make contingency plans for changing times zones, acclimatisation to altitude and competing in cold temperatures (tables 1 and 2).

\section{INJURY PREVENTION AND SPORTS SAFETY}

During the 2018 PyeongChang Paralympic Winter Games, $20 \%$ of all athletes sustained an injury, ${ }^{3}$ compared with $12 \%$ of those participating in the corresponding Olympic Games. ${ }^{67}$ The pattern during the 2014 Paralympic Winter Games in Sochi was similar, with corresponding injury rates of $24.5 \%$ vs $12 \% .{ }^{2}{ }^{68}$ Most of the injuries during the Paralympic Games were acute, and not unexpectedly, Para alpine/snowboarding events demonstrated the highest rates. During the Sochi Paralympic Games, poor snow conditions due to warm weather may have contributed to injuries. ${ }^{2}$ It is important when preparing the snow to consider that the Paralympic Games will be held almost 4 weeks after the Olympic Games.

During the PyeongChang Paralympic Winter Games, the incidence of injuries in the Para alpine events declined compared with the previous Paralympic Games, possibly due to preventive measures such as racecourse optimisation, allowing more training runs, and the possibility to change starting times. ${ }^{3}$ However, the incidence of snowboarding injuries, primarily to the head/face/ neck and lower leg, remained high. Para snowboarding is a relatively new sport, and inexperienced and faulty techniques could have contributed to these injuries, requiring appropriate education. ${ }^{3}$ Yet, few studies describe the injury pattern specifically in Para Nordic skiing, but existing studies have shown that shoulder injuries are a concern. ${ }^{3}$

The various impairments which Para athletes have, along with the adapted equipment being used, often contribute to injuries. ${ }^{49}$ Therefore, each athlete could benefit from a risk analysis designed to develop appropriate preventive measures before travelling to Beijing. Furthermore, each athlete should be monitored continuously through injury and illness surveillance adapted to Para athletes before and under competition. ${ }^{34}{ }^{40}$ Moreover, secondary and tertiary treatment of injuries should be planned. For example, in case of catastrophic injury, first responders must know how to release the athlete from special equipment such as sit-skis, sledges and wheelchairs. In addition, medical staff must know how 
to deal with serious trauma to athletes who already have some form of impairment, such as the bone mass, spinal cord, brain or cardiopulmonary system.

\section{CONCLUSIONS AND FUTURE PERSPECTIVES}

As described in detail above, the demands associated with Para winter sports events may be complicated by the elevated altitude in Beijing, potentially cold temperatures, challenges of travelling across multiple time zones, and potential limitations due to the COVID-19 pandemic. Here, we propose that extra caution is required for Para athletes since altitude acclimatisation may take a longer time, clothing is more crucial, and travel preparations, as well as jetlag considerations, are more extensive. Taking all these factors into consideration, we have attempted to formulate recommendations for athletes preparing for the Beijing 2022 Winter Paralympics (tables 1 and 2)

As already emphasised, many of these recommendations are based on limited scientific evidence for Para athletes, and we would like to clarify that this paper is based on non-consensus recommendations. In the future, more sophisticated experiments and observational studies focusing specifically on Para winter sports are warranted. These should employ new technology to simultaneously monitor performance indicators, physiological responses, injuries and environmental factors in connection with altitude training, exposure to cold temperatures and travel across time zones. Despite the limitations, we hope that our recommendations will be of value for athletes preparing to compete in the 2022 Beijing Paralympic Winter Games and beyond.

\section{Twitter K Fagher @KristinaFagher}

Contributors $\mathrm{KF}$ and $\mathrm{HCH}$ conceptualised and wrote the first draft of this manuscript. $\emptyset \mathrm{S}, \mathrm{JKB}, \mathrm{GSS}$ and JL provided input and contributed equally to writing towards final version of this manuscript.

Funding KF is funded by The Swedish Research Council of Sports Sciences (D2021-0018).

Competing interests None declared.

Patient consent for publication Not applicable.

Provenance and peer review Not commissioned; externally peer reviewed.

Open access This is an open access article distributed in accordance with the Creative Commons Attribution Non Commercial (CC BY-NC 4.0) license, which permits others to distribute, remix, adapt, build upon this work non-commercially, and license their derivative works on different terms, provided the original work is properly cited, appropriate credit is given, any changes made indicated, and the use is non-commercial. See: http://creativecommons.org/licenses/by-nc/4.0/.

ORCID iD

K Fagher http://orcid.org/0000-0002-9524-7553

\section{REFERENCES}

1 BOC. Beijing organising Committee for the 2022 Olympic and Paralympic winter games: official website of Beijing organising Committee for the 2022 Olympic and Paralympic winter games, 2021. Available: https://www.beijing2022.cn/a/20190130/008852. $\mathrm{htm}$ [Accessed 12 Dec 2021].

2 Derman W, Schwellnus MP, Jordaan E, et al. High incidence of injury at the Sochi 2014 winter Paralympic games: a prospective cohort study of 6564 athlete days. Br J Sports Med 2016;50:1069-74.
3 Derman W, Runciman P, Jordaan E, et al. High incidence of injuries at the Pyeongchang 2018 Paralympic winter games: a prospective cohort study of 6804 athlete days. Br J Sports Med 2020;54:38-43.

4 Fagher K, Dahlström Örjan, Jacobsson J, et al. Injuries and illnesses in Swedish Paralympic athletes-A 52-week prospective study of incidence and risk factors. Scand J Med Sci Sports 2020;30:1457-70.

5 Carlsen CH, Kathrin Baumgart J, Kocbach J, et al. Framework for In-Field analyses of performance and Sub-Technique selection in standing para Cross-Country skiers. Sensors 2021;21. doi:10.3390/ s21144876. [Epub ahead of print: 17 Jul 2021].

6 Baumgart JK, Haugnes P, Bardal LM, et al. Development of a framework for the investigation of speed, power, and kinematic patterns in para Cross-Country Sit-Skiing: a case study of an LW12 athlete. Front Sports Act Living 2019;1:4.

7 Joyner MJ, Coyle EF. Endurance exercise performance: the physiology of champions. J Physiol 2008;586:35-44.

8 Losnegard T. Energy system contribution during competitive crosscountry skiing. Eur J Appl Physiol 2019;119:1675-90.

9 Sandbakk Øyvind, Holmberg H-C. Physiological capacity and training Routines of elite Cross-Country skiers: approaching the upper limits of human endurance. Int J Sports Physiol Perform 2017;12:1003-11.

10 Gastin PB. Energy system interaction and relative contribution during maximal exercise. Sports Med 2001;31:725-41.

11 Laaksonen MS, Jonsson M, Holmberg H-C. The Olympic Biathlon - Recent Advances and Perspectives After Pyeongchang. Front Physiol 2018;9:796.

12 Gilgien M, Reid R, Raschner C, et al. The training of Olympic alpine Ski Racers. Front Physiol 2018;9:9.

13 Vernillo G, Pisoni C, Thiébat G. Physiological and physical profile of Snowboarding: a preliminary review. Front Physiol 2018;9:770-70.

14 Goll M, Wiedemann MSF, Spitzenpfeil P. Metabolic demand of Paralympic alpine skiing in Sit-Skiing athletes. J Sports Sci Med 2015;14:819-24.

15 IPC. Explanatory guide to Paralympic classification. International Paralympic Committee, 2020. Available: https://www.paralympic. org/sites/default/files/2020-10/2020_10\%20Explanatory\% 20Guide\%20to\%20Classification_Winter\%20Sports.pdf

16 Baumgart JK, Brurok B, Sandbakk Øyvind, Sandbakk O. Peak oxygen uptake in Paralympic sitting sports: a systematic literature review, meta- and pooled-data analysis. PLoS One 2018;13:e0192903.

17 Thijssen DHJ, Steendijk S, Hopman MTE. Blood redistribution during exercise in subjects with spinal cord injury and controls. Med Sci Sports Exerc 2009;41:1249-54.

18 Gee CM, Currie KD, Phillips AA, et al. Spinal cord injury impairs cardiovascular capacity in elite wheelchair rugby athletes. Clin $J$ Sport Med 2020;30:33-9.

19 Tweedy SM, Beckman EM, Geraghty TJ, et al. Exercise and sports science Australia (ESSA) position statement on exercise and spinal cord injury. J Sci Med Sport 2017;20:108-15.

20 Kang J, Robertson RJ, Goss FL, et al. Metabolic efficiency during arm and leg exercise at the same relative intensities. Med Sci Sports Exerc 1997;29:377-82

21 Baumgart JK, Gürtler L, Ettema G, et al. Comparison of peak oxygen uptake and exercise efficiency between upper-body Poling and arm crank ergometry in trained paraplegic and able-bodied participants. Eur J Appl Physiol 2018;118:1857-67.

22 Calbet JAL, Holmberg $\mathrm{H}-\mathrm{C}$, Rosdahl $\mathrm{H}$, et al. Why do arms extract less oxygen than legs during exercise? Am J Physiol Regul Integr Comp Physiol 2005;289:R1448-58.

23 Leicht C, Perret C. Comparison of blood lactate elimination in individuals with paraplegia and able-bodied individuals during active recovery from exhaustive exercise. J Spinal Cord Med 2008;31:60-4.

24 Mengelkoch LJ, Kahle JT, Highsmith MJ. Energy costs \& performance of transtibial amputees \& non-amputees during walking \& running. Int J Sports Med 2014;35:1223-8.

25 Gjovaag T, Starholm IM, Mirtaheri P, et al. Assessment of aerobic capacity and walking economy of unilateral Transfemoral amputees. Prosthet Orthot Int 2014;38:140-7.

26 Starholm IM, Mirtaheri P, Kapetanovic N, et al. Energy expenditure of transfemoral amputees during floor and treadmill walking with different speeds. Prosthet Orthot Int 2016;40:336-42.

27 Ward KH, Meyers MC. Exercise performance of lower-extremity amputees. Sports Med 1995;20:207-14.

28 Beck ON, Grabowski AM. Athletes with versus without leg amputations: different biomechanics, similar running economy. Exerc Sport Sci Rev 2019;47:15-21. 
29 de Groot S, Dallmeijer AJ, Bessems PJC, et al. Comparison of muscle strength, sprint power and aerobic capacity in adults with and without cerebral palsy. J Rehabil Med 2012;44:932-8.

30 Hombergen SP, Huisstede BM, Streur MF, et al. Impact of cerebral palsy on health-related physical fitness in adults: systematic review. Arch Phys Med Rehabil 2012;93:871-81.

31 Prins L. An elite runner with cerebral palsy: cost of running determines athletic performance. S Afr J Sports Med 2016;28:27-9.

32 Runciman P, Derman W. The athlete with cerebral palsy: challenges for the team physician. Aspetar Sport Med J 2018;7:142-7.

33 De Groot S, Janssen TWJ, Evers M, et al. Feasibility and reliability of measuring strength, sprint power, and aerobic capacity in athletes and non-athletes with cerebral palsy. Dev Med Child Neurol 2012;54:647-53.

34 Ferreira S, Tucker R, Runciman P. Effects of exercise training on performance and function in individuals with cerebral palsy: a critical review. S Afr J Res Sport Phys Educ Recreat 2016;38:177-93.

35 Malwina KA, Krzysztof M, Piotr Z. Visual impairment does not limit training effects in development of aerobic and anaerobic capacity in tandem cyclists. J Hum Kinet 2015;48:87.

36 Silva PR, Mainenti M, Felicio L. Cardiorespiratory fitness of visually impaired footballers through direct and indirect methods: a pilot study. J Exerc Physiol Online 2018;21.

37 Ray CT, Horvat M, Croce R, et al. The impact of vision loss on postural stability and balance strategies in individuals with profound vision loss. Gait Posture 2008;28:58-61.

38 Skaggs S, Hopper C. Individuals with visual impairments: a review of psychomotor behavior. Adapt Phys Activ Q 1996;13:16-26.

39 Burtscher M, Niedermeier M, Burtscher J, et al. Preparation for endurance competitions at altitude: physiological, psychological, dietary and coaching aspects. A narrative review. Front Physiol 2018:9:1504

40 Wehrlin JP, Hallén J. Linear decrease in .VO2max and performance with increasing altitude in endurance athletes. Eur J Appl Physiol 2006;96:404-12.

41 Chapman RF. The individual response to training and competition at altitude. Br J Sports Med 2013;47 Suppl 1:i40-4.

42 Roberts SSH, Teo W-P, Warmington SA. Effects of training and competition on the sleep of elite athletes: a systematic review and meta-analysis. Br J Sports Med 2019;53:513-22.

43 Kinsman TA, Hahn AG, Gore CJ, et al. Respiratory events and periodic breathing in cyclists sleeping at 2,650-m simulated altitude. $J$ Appl Physiol 2002;92:2114-8.

44 Roberts IE, Murphy CJ, Goosey-Tolfrey VL. Sleep disruption considerations for Paralympic athletes competing at Tokyo 2020. J Sports Med Phys Fitness 2021;61:1159-72.

45 Chapman RF, Karlsen T, Resaland GK, et al. Defining the "dose" of altitude training: how high to live for optimal sea level performance enhancement. J Appl Physiol 2014;116:595-603.

46 Mujika I, Sharma AP, Stellingwerff T. Contemporary Periodization of altitude training for elite endurance athletes: a narrative review. Sports Med 2019;49:1651-69.

47 Millet GP, Roels B, Schmitt L, et al. Combining hypoxic methods for peak performance. Sports Med 2010;40:1-25.

48 Chapman RF, Karlsen T, Ge R-L, et al. Living altitude influences endurance exercise performance change over time at altitude. $J$ Appl Physiol 2016;120:1151-8.

49 Sandbakk Ø, Solli GS, Talsnes RK. Preparing for the Nordic skiing events at the Beijing Olympics in 2022: evidence-based recommendations and unanswered questions. $J$ of Sci in Sport Exerc 2021:3:257-69.

50 Layden JD, Patterson MJ, Nimmo MA. Effects of reduced ambient temperature on fat utilization during submaximal exercise. Med Sci Sports Exerc 2002;34:774-9.

51 Oksa J. Neuromuscular performance limitations in cold. Int $J$ Circumpolar Health 2002;61:154-62.

52 Flore P, Therminarias A, Oddou-Chirpaz MF, et al. Influence of moderate cold exposure on blood lactate during incremental exercise. Eur J Appl Physiol Occup Physiol 1992;64:213-7.

53 Sandsund M, Sue-Chu M, Helgerud J, et al. Effect of cold exposure (-15 degrees $\mathrm{C}$ ) and salbutamol treatment on physical performance in elite nonasthmatic cross-country skiers. Eur J Appl Physiol Occup Physiol 1998;77:297-304.

54 Quirion A, Laurencelle L, Paulin L, et al. Metabolic and hormonal responses during exercise at $20^{\circ}, 0^{\circ}$ and $-20^{\circ} \mathrm{C}$. Int $\mathrm{J}$ Biometeorol 1989;33:227-32.
55 Beelen A, Sargeant AJ. Effect of lowered muscle temperature on the physiological response to exercise in men. Eur J Appl Physiol Occup Physiol 1991;63:387-92.

56 Wiggen Øystein N, Heidelberg CT, Waagaard SH, et al. The effects of cold environments on Double-Poling performance and economy in male Cross-Country skiers wearing a standard racing suit. Int $J$ Sports Physiol Perform 2016;11:776-82.

57 Forbes-Robertson S, Dudley E, Vadgama P, et al. Circadian disruption and remedial interventions: effects and interventions for jet lag for athletic peak performance. Sports Med 2012;42:185-208.

58 Janse van Rensburg DCC, Jansen van Rensburg A, Fowler P, et al. How to manage travel fatigue and jet lag in athletes? A systematic review of interventions. Br J Sports Med 2020;54:960.

59 Manfredini R, Manfredini F, Fersini C, et al. Circadian rhythms, athletic performance, and jet lag. Br J Sports Med 1998;32:101-6.

60 Waterhouse J, Reilly T, Edwards B. The stress of travel. J Sports Sci 2004;22:946-66.

61 Halson SL, Burke LM, Pearce J. Nutrition for travel: from jet lag to catering. Int J Sport Nutr Exerc Metab 2019;29:228-35.

62 Svendsen IS, Taylor IM, Tønnessen E, et al. Training-related and competition-related risk factors for respiratory tract and gastrointestinal infections in elite cross-country skiers. $\mathrm{Br} J$ Sports Med 2016;50:809-15.

63 Halson SL. Sleep in elite athletes and nutritional interventions to enhance sleep. Sports Med 2014;44 Suppl 1:13-23.

64 O'Donnell S, Beaven CM, Driller MW. From pillow to podium: a review on understanding sleep for elite athletes. Nat Sci Sleep 2018;10:243-53

65 Reilly T, Edwards B. Altered sleep-wake cycles and physical performance in athletes. Physiol Behav 2007;90:274-84.

66 Bogdos M. A Paralympic Games during the global pandemic: from preparation to performance and the lessons in-between VISTA. virtual conference, 2021

67 Soligard T, Palmer D, Steffen K, et al. Sports injury and illness incidence in the PyeongChang 2018 Olympic winter games: a prospective study of 2914 athletes from 92 countries. Br J Sports Med 2019:53:1085-92.

68 Soligard T, Steffen K, Palmer-Green D, et al. Sports injuries and illnesses in the Sochi 2014 Olympic winter games. Br J Sports Med 2015;49:441-7.

69 Fagher K, Dahlström Örjan, Jacobsson J, et al. Prevalence of sports-related injuries and illnesses in Paralympic athletes. $P m R$ 2020;12:271-80

70 Derman W, Badenhorst M, Blauwet C, et al. Para sport translation of the IOC consensus on recording and reporting of data for injury and illness in sport. Br J Sports Med 2021;55:1068-76.

71 Theisen D. Cardiovascular determinants of exercise capacity in the Paralympic athlete with spinal cord injury. Exp Physiol 2012;97:319-24.

72 Kamaraj DC, Dicianno BE, Cooper RA, et al. Acute mountain sickness in athletes with neurological impairments. J Rehabil Res Dev 2013;50:253-62.

73 Dodge NN. Cerebral palsy: medical aspects. Pediatr Clin North Am 2008:55:1189-207.

74 Runciman P, Tucker R, Ferreira S, et al. Paralympic athletes with cerebral palsy display altered pacing strategies in distancedeceived shuttle running trials. Scand J Med Sci Sports 2016;26:1239-48.

75 Handrakis JP, Trbovich M, Hagen EM, et al. Thermodysregulation in persons with spinal cord injury: case series on use of the autonomic standards. Spinal Cord Ser Cases 2017;3:17086.

76 Griggs KE, Stephenson BT, Price MJ, et al. Heat-related issues and practical applications for Paralympic athletes at Tokyo 2020. Temperature 2020;7:1:37-57.

77 Cameron M, Lacroix M, Stellingwerff T. Physiological considerations to support Podium performance in Para-Athletes. Front Rehab Scie2021;2

78 Vanlandewiijck YC, Thompson WR. Training and coaching the Paralympic athlete. Singapore: Wiley Blackwell, 2017.

79 Lockley SW, Arendt J, Skene DJ. Visual impairment and circadian rhythm disorders. Dialogues Clin Neurosci 2007;9:301-14

80 Fagher K. Sports-related injuries and illnesses in Paralympic athletes. Lund: Lund University, Faculty of Medicine Doctoral Dissertation Series, 2019. 